\title{
'Our Long National Nightmare Is Over': the resolution of trauma and male melodrama in The Tree of Life
}

Brian Baker

At the beginning of The Trauma Question (2008), Roger Luckhurst notes that the first appearance of Post-Traumatic Stress Disorder (PTSD) in the American Psychiatric Association's diagnostic manual was in 1980. 'The arrival of PTSD helped consolidate a trauma paradigm that has come to pervade the understanding of subjectivity and experience in the advanced industrial world', he writes (Luckhurst 2008: 1):

Each successive edition of the Diagnostic Manual has expanded the categories of those who might be diagnosed with PTSD. At first PTSD was only attributable to those who were directly involved, but 'secondary' victim status now includes witnesses, bystanders, rescue workers, relatives caught up in the immediate aftermath, a proximity now extended to include receiving news of the death or injury of a relative. An understanding of the psychological consequences of trauma have percolated into many different context, and Western cultures have convulsed around iconic trauma events. (Luckhurst 2008: 1).

Published in 2008, The Trauma Question is situated, inevitably, in the sociocultural lee of the events of 9/11. Luckhurst's rhetorical strategy, to open in 1980 rather than 2001, deliberately breaks the sense that 9/11 was some kind of epistemic shift. Although many texts of cultural criticism that consider trauma, such as E. Ann Kaplan's Trauma Culture (2005) are directly related to 9/11, other crucial texts, such as Cathy Caruth's Unclaimed Experience (1996) predate this historical moment and have other referents: World War I, the Holocaust, or the Vietnam War. The experience of veterans in Vietnam, and the problematic processes of healing and reintegration that they endured upon their return from 
duty, has been a recurrent motif in American considerations of trauma since the early 1970s. Robert Jay Lifton's book on his experiences with the 'rap groups' formed by Vietnam War veterans, Home From The War (1973), pursues the feelings of 'survivor guilt' felt by the veterans, resulting in psychological disturbance and dislocation:

The predominant emotional tone [...] is all-encompassing absurdity and moral inversion. The absurdity has to do with a sense of being alien and profoundly lost, yet at the same time locked into a situation as meaningless as unreal as it is deadly. (Lifton 1973: 37)

The title of Lifton's book is deeply ironic: having 'come home', the Vietnam veterans felt an ongoing alienation and isolation that prevented them from reintegrating successfully into a society that itself was ambivalent about the war and the United States' involvement in it.

The relation between trauma and survival is crucial to Caruth's investigation in Unclaimed Experience (1996). She writes:

What Freud encounters in the traumatic neurosis is not the reaction to any horrible event but, rather, the peculiar and perplexing experience of survival. If the dreams and flashbacks of the traumatised thus engage Freud's interest, it is because they bear witness to a survival that exceeds the very claims and consciousness of the one who endures it. At the heart of Freud's rethinking of history in Beyond the Pleasure Principle, I would thus propose, is the urgent and unsettling question: What does it mean to survive? (Caruth 1996: 60, italics in original)

Much of Caruth's book considers what she describes as 'the paradoxical situation between survival and consciousness' (Caruth 1996: 61) that is present in Freud's theorisation of trauma, an approach that Roger Luckhurst suggests 'turns on the device of the aporia, or unresolvable paradox' (Luckhurst 2008: 5). Luckhurst argues that Caruth draws upon the work of Freud; the deconstructive theories and critical strategies of Jacques Derrida, Paul de Man and other Yale 
academics (of which Caruth was one); and Theodor Adorno and Jean-François Lyotard in developing her 'theory of aporetic trauma'. Luckhurst particularly identifies a circuit between Lyotard and Freud, when:

Lyotard explicitly evoked the Freudian idea of the paradoxically registered yet unregistered trauma, portraying modernity as something insistently haunted by what it had violently suppressed or forgotten in the symptom that 'would signal itself even in the present as a spectre'. (Luckhurst 2008: 6)

As I will set out later in this chapter, a critical figure in which the repression, the aporia or the textual 'silence' characterizes the cultural work associated with trauma and traumatic events is one that is recurrent in certain modes of textual analysis, and I will consider the importance of the Freud-inflected Marxist critical practice of Pierre Macherey in A Theory of Literary Production (1989) as well as theorists and critics of film melodrama later in this chapter. While my own methodology is certainly indebted to that of Macherey, and I will be using a Freudian set of references to pursue representations of trauma, this should be considered a strategic rather than wholeheartedly Freudian mode of enquiry; but it is there that we will begin.

Roger Luckhurst notes that 'Caruth's small body of work has been extremely influential' (Luckhurst 2008: 5), cementing psychoanalytical frameworks into cultural criticism that investigates trauma and its representation. Freud's own analysis of trauma is foundational to his early and late work, from Freud (and Joseph Breuer's) first book on psychological disturbance, Studies On Hysteria (1895/1956), to Beyond the Pleasure Principle (1922/2006) in which Freud outlined his theory of the 'stimulus shield' that protects the psyche from being overwhelmed by the shocks of modernity. 
'Hysteria', the term used in Studies On Hysteria, is, of course, a gendered term, used to denote psychological disturbance in women (and connected, in classical medicine, to the mobility of the womb around the female body). Freud and Breuer diagnose the return of memory as being central to traumatic experience and to hysteria. 'It is of course obvious that in the cases of "traumatic" hysteria,' they write, 'what provokes the symptoms is the accident. The causal connection is equally evident in hysterical attacks when it is possible to gather from the patient's utterances that in each attack he is hallucinating the same event which provoked the first one' (Freud and Breuer 1956: 4). They continue: 'The disproportion between the many years' duration of the hysterical symptom and the single occurrence which provoked it is what we are accustomed invariably to find in traumatic neuroses. Quite frequently it is some event in childhood that sets up a more or less severe symptom which persists during the years that follow' (Freud and Breuer 1956: 4). I shall suggest the importance of this to a reading of The Tree of Life shortly.

Freud's later understanding of trauma and its effects were deeply influenced by his experience of treating Great War veterans for the psychological symptoms produced by their experience of conflict. In his 'Introduction to Psycho-Analysis and the War Neuroses' (a literal Introduction to a book), Freud initially differentiates war neuroses from 'the ordinary neuroses of peace-time' by his emphasis on trauma: they 'are to be regarded as traumatic neuroses whose occurrence has been made possible or has been promoted by a conflict in the ego' (Freud 1955a: 209). By the end of the Introduction, Freud makes a clear analogy between peace-time neuroses, caused by the libido (desire) and its repression, and war-time neuroses, caused by the fear of external violence. At 
the very end of the Introduction he states: 'we have a perfect right to describe repression, which lies at the basis of every neurosis, as a reaction to a trauma as an elementary traumatic neurosis' (Freud 1955a: 210). The implication of this statement is that the war neurosis is in no sense originary: it replicates the conditions of repression that form the pattern of subjectivity Freud outlines in his theory of Oedipal conflict (and ultimately, as the motive force which provides the energies for cultural and social production, for 'civilization'). In Moses and Monotheism (1939/1951), Freud argues that 'it is correct to say that there are cases which we single out as "traumatic" ones because the effects unmistakably go back to one or more strong impressions of this early period [of infancy]' (Freud 1951: 118). If war neurosis is analogous to peacetime neurosis in the ego defending itself from trauma, then trauma becomes foundational to the operation of repression in the peace-time ego itself.

The soldier, particularly the 'veteran' or 'damaged' homecoming combatant, has become an emblematic figure in post-Vietnam War US culture. As Roger Luckhurst notes, however, trauma seems all too transmissible. Although the effects and aftermath of war seem to be crucial motivating events in a shift from a focus on theories and analysis of hysteria from women to men, the investigation of forms of 'male hysteria' extends back to the work of Jean-Martin Charcot (1825-1893). As Lynne Kirby notes in Parallel Tracks, in the work of Charcot, 'the similarity of the symptoms [of 'male hysteria'] to those of female hysterics' was apparent, as was the surprising number of 'stereotypically virile working-class men' who presented these symptoms (Kirby 1997: 66). Charcot connected the symptoms of male hysteria to displacement and mobility in men, 'vagabonds, tramps, society's peripatetic disenfranchised [...] who experience in 
their own bodies and lives the metaphor of a characteristic trait of hysteria mobility' (Kirby 1997: 67). Kirby suggests that hysteria can be understood as being produced by the conditions of modernity itself:

One can see that cultural displacement as massive as nineteenth-century mechanization and urbanization - railway-assisted - traumatized its victims into a condition akin to female hysteria. In other words, it "emasculated" men, and not only those men of a certain class. Women, proletarian men, tramps, and other social marginals were made to bear the brunt of the shocks of modernity. (Kirby 1997: 67)

Kirby argues that 'the working-class male hysterics pointed to what all men were potentially capable of becoming' (Kirby 1997: 68). The hysteria and trauma suffered by the soldier, by the displaced, and by proletarian masculinity, haunts all forms of male subjectivity in modernity.

Cultural diagnoses of trauma, affecting not individuals but populations, gained particular urgency in the United States after $9 / 11$. The focus of texts such as Kaplan's Trauma Culture is upon personal testimony and witness, and but also builds upon those personal responses to the aftermath of 9/11 in New York to consider the social and cultural means by which responses to trauma could engage with a therapeutics, and in which critical texts on trauma achieve a kind of cultural work. They are not only about trauma, but the critical investigation of the responses to 9/11 among the citizens of New York City assumes a responsibility to effect if not healing, then an engagement with an ongoing process of coming-to-terms. Kaplan's text engages with the practices and framing of personal memory while asserting its need to insert these memories into broader cultural practices of memorialization and the construction of a public history. This sense of continuity is itself therapeutic, providing a means by which a corrosive apocalypticism may be diffused and defused. 
The focus of this chapter is on Terrence Malick's The Tree Of Life (2011). The Tree Of Life narrates what seems a fairly conventional domestic story, largely from the point of view of Jack (Sean Penn), a successful but spiritually bereft architect who meditates on the loss, as a young man, of his younger brother R.L. (Laramie Eppler). If, in the most famous quotation from Studies on Hysteria, Freud and Breuer declare: 'Hysterics suffer mainly from reminiscences' (Freud and Breuer 1956: 7 [italics in original])., then jack may be said to be suffering from a form of masculine hysteria, caused by trauma. In the course of a day, the anniversary of his brother's death, he remembers their upbringing in Waco, Texas, during the 1950s, and the film deploys motifs from classic 1950s melodrama: an evocation of a sunny summer town and family life; father-son/ Oedipal conflict; rites of passage; the failures of authoritarian patriarchal masculinity. The film is presented in an extraordinary way, as a series of moments, often of striking beauty, in which dialogue is generally absent (which becomes crucial thematically), time is dislocated on a local, global and cosmological scale (seconds, minutes, years, decades, eons), but a sense of wonderment at (and the wonderment of) life is immanent. This wonderment, even bewilderment, is carried not only in the extraordinary image-track, but also in the device of the disembodied voice over, in which baffled and self questioning voices express the interiority of key characters. The voice(s)-over indicate the spiritual questioning of Jack, his father (Brad Pitt) and his mother (Jessica Chastain), indicating not only their stricken and doubting relationship to the divine, but the fact that younger son R.L. is the moral, or perhaps theological/spiritual centre of the film, as the other characters connect to God through him. The film concludes with a visionary sequence in which Jack appears 
to find some kind of redemption and happiness, through finding his brother again, in a spiritual sense.

In this chapter, The Tree of Life will be read as a response to trauma and suffering, particularly in a post $9 / 11$ context. In a sense, it will be read as a film made in the time of war. This is something of a counter-reading to prevailing critical orthodoxy on the film, as we shall see shortly. There will be no recourse to simple symptomology here, however, nor to read Jack and his experiences as simply symptoms of the return of a past traumatic event. Instead, the chapter will trace the persistence of a discourse of hysteria in criticism of film melodrama, which has been read by Rodowick and [others] as a genre that structurally engages a psychoanalytical process. Critics of film melodrama have proposed that crucial ideological premises and implications of the narrative are repressed by the narrative, which then return as an excess of visual stylisation and emotional affect (which leads to the common usage of the word 'melodramatic' to mean overtly performative and emotionally false). Where the critical reception of the film has concentrated on religious or philosophical readings, I will concentrate on the genres of melodrama and science fiction. The Tree Of Life is a generically hybrid text, in that it brings together the Oedipal drama of the classic male melodrama of the 1950s with religious, philosophical or even a cosmological ideas and images, with imagery drawn from a particular kind of science fiction spectacle. I will argue that the film's generic hybridity is a kind of structural and theological fix for the problematic freight of the melodrama narrative and for material that cannot be ideologically acknowledged within the cultural circumstances of the film's production.

These circumstances - the aftermath of $9 / 11$, the War on Terror, Barack 
Obama's first Administration - play little part in history of critical reception of The Tree Of Life. Much of this is directly auteurist in emphasis, regarding the film in the light of Malick's ongoing concern with the spiritual and its relation to nature and to the human. More particularly, this auteurism is connected to an emphasis on Malick's Catholicism and to the films overt use of the Book of Job as intertext and thematic point of reference. Indeed, the film opens with a quotation from Job, wherein God asks him where he was at the moment of Creation, a reminder for the supplicant of his relative insignificance in the greater scheme of things. In relation to the film's deployment or science fiction spectacle, which produces a spectatorship defined by awe and wonder, this might be seen as someone didactic or even authoritarian: where were you when this film was created? There has been critical debate about the use of spectacle sequences in relation to the film's religious themes (or even, as Robert Sinnerbrink and David Sterritt suggest, in relation to its 'religiosity' (Sinnerbrink 2012: 104, Sterritt 2011: 52)), but largely critics have attempted to approach the film as a selfcontained object (art object, in fact) which offers a meditation on the human connection with the divine, rather than analysing the film through genre. While I will suggest that there is a form of textual 'repression' at work, this will be read through ideological and generic frameworks rather than as an expression of auteurist sensibility.

The Tree of Life was Terrence Malick's fifth major film and followed, after a long hiatus, The Thin Red Line (1998) and The New World (2005). The Thin Red Line is of particular concern here, as it is a war film, an adaptation of James Jones' novel (1962), which narrates the US Army assault on a Japanese-held Pacific Island during the closing months of World War II. Released in close proximity to 
the intense aural and visual 'realism' of Stephen Spielberg's Saving Private Ryan (1998), The Thin Red Line instead offered a more philosophical and perhaps lyrical or poetic presentation of conflict. In contrasting the geopolitical conflict with images of the island's nature and landscape, as well as its indigenous peoples, the film appears to stage a collision between the temporal/ political and the natural/ timeless. This is partly articulated in terms of the personal struggles of certain American GIs, whose speculations and alienation serves to critique and displace human activity. Formally, The Thin Red Line uses similar techniques to The Tree Of Life - expressive natural spectacle, theological questions offered in voice-over, temporal disjunction - to construct its sense of otherworldliness, and spiritual and philosophical speculation.

As Bernard G. Prusak notes in a short response to The Tree of Life in Commonweal (2014), '[p]hilosophers who have written about the films of Terrence Malick typically note three biographical facts' (Kilby, Johnson and Prusak 2014: 16): firstly, he studied under Stanley Cavell at Harvard; secondly, he went to Oxford where he studied with Gilbert Ryle; and thirdly, on his return to the USA and MIT, he taught a class on Heidegger and published a translation of some of his work. Perhaps even more pertinently, Malick grew up in and still professes a devout Catholic faith. This is most evident in The Tree of Life, which begins with a voice-over by the mother, who declares that there are two paths in life: the way of Nature and the way of Grace. Eldest son Jack, like his father, takes the path of nature, the harder road; the younger son R.L. follows the mother in the way of grace. This dichotomy striates the entire film, but ultimately its vision of redemption is a deeply devout one, and is available to all; it is represented, as we shall now investigate, by the visual rhetoric of science fiction spectacle. 
Both Robert Sinnerbrink, in 'Cinematic Belief' (2012) and David Sterritt in 'Days of Heaven and Waco' (2011) are critics who approach the matter of genre in The Tree of Life. Sinnerbrink identifies three 'narrative layers' (or generic overlays) that constitute The Tree of Life: (1) familial melodrama; (2) 'the historical-spiritual story, the way the O'Brien's family story depicts [...] a "Fall" narrative from the romanticised historical "Eden" of the 1950s Midwest to the spiritually destitute space of contemporary urban America' (105); and (3) 'the cosmological creation myth' (105). While I take issue with the characterization of 1950s America as 'Eden' in The Tree of Life, Sinnerbrink's thoughtful and detailed article provides a means to conceptualise the film's generic hybridity. Sterritt's review-article is a less detailed, more immediate response to the film, but he identifies key generic elements - 'psychological drama, domestic melodrama, coming-of-age tale, family romance' (Sterritt 2011: 52), which are close to synonymous - and then proposes that the film 'puts genre elements into play for the purpose of exceeding and transcending them, using them as building blocks for a risky, resourceful tour de force that moves from earthy, psychological concerns to heavenly, sacramental ones' (52). We should note here the connection between genre and excess, the rupturing of boundaries; as we shall see, many film critics have noted that excess is a significant characteristic of melodrama itself. Sterritt notes that 'the film is often as muddled as its less imaginative critics have claimed' (52), indicating that, although the film won the 2011 Palme d'Or at the Cannes Film Festival, initial critical reception was somewhat mixed, viewers have difficulty in welding together a complete reading or vision of the film from its disparate components. 
This, I suggest, is deliberate and symptomatic rather than simply evidence of the film's global incoherence, but it is little wonder that most critical writing on the film tends to downplay the issue of genre and focus on the philosophical or spiritual matter. Brent S. Plate's well-cited article 'Visualising the Cosmos' (2012) for instance, instead places the film in a long (textual) tradition of representations of the cosmos, from Hartman Schedel's Nuremberg Chronicles of 1493 to Darwin's evolutionary tree included in the 1859 Origin of Species. This suggests that the film itself privileges a reading that masks or represses genre and ideology and instead encourages what George B. Handley, citing Kent Jones, calls the 'wonder of presence' (Handley 2014: 80). This mode of 'wonder', connected to the visual strategies of the cinematic sublime, sutures the film together as a philosophical whole, albeit one that clearly did not work for a large proportion of viewers. As Plate notes, ‘[c]ritics and audiences [...] fumbling to place it within a proper cinematic frame of reference [...] only com[e] up with connections to Stanley Kubrick's 2001: A Space Odyssey (1968)' (Plate2012: 528); we can see this reference in Sterritt's article and Russell J.A. Kilbourn's '(No) Voice Out Of The Whirlwind' (2014), which concentrates largely on the film's relation to the Book of Job. That 2001: A Space Odyssey is a recurrent point of reference indicates the use of the visual strategies of the cinematic sublime (in particular special effects and spectacle sequences) that are synonymous with science fiction cinema. Scott Bukatman, in Matters of Gravity (2003), suggest that 'optical effects sequences generate revelation through kinetic exploration' (Bukatman 2003: 118) and that in the imaging technologies of contemporary spectacular science fiction, 'technology becomes a new source for exaggerated sensual and sensory pleasures' (Bukatman 2003: 130). What characterises the 
effects (and affect) of science fiction cinema is 'a phenomenological excess that alludes to a reality beyond the ordinary - "a world of endless, enchanting, metamorphosis"' (Bukatman 2003: 119). While noting, once more, the critical discourse of excess, the important point here is that it is the generic markers of science fiction spectacle which produce the effect of the transcendent or the representation of the unrepresentable: the divine. This is why The Tree of Life has recourse to this visual register, but these gestures towards the transcendent, as I will argue, occlude the contemporary social and ideological fabric.

The film begins in what we must assume - by Brad Pitt's glasses and haircut, and the cut of his white shirt, which inescapably bring to mind Robert McNamara and the Kennedy and Johnson administrations - to be the mid- to late-1960s. The house is High Modernist: rectangular, white, large rectilinear windows opening onto gardens. It is a house that bespeaks the utopian and technocratic dreams of the 1960s rather than the comfortable, conformist suburbia of the 1950s, and in particular the small-town house that we will see later in the film as the family residence. A young man brings a telegram to a house, and when the mother - Jessica Chastain - opens it, it brings news of the death of a favourite son, a trauma so profound that none of the surviving family members seem able to get over it. Although this moment is read by George B. Handley as 'at least consistent with a suicide', citing the fact that 'Malick's own younger brother committed suicide in his early twenties' (Handley 2014: 86), I read the official delivery by telegram as crucial, as is the death of R.L. at 19 years old, the average age of the combat soldier in Vietnam. The fact that this crucial traumatic event for the narrative, the direct motivation for Jack's spiritual difficulties and the film's emblem of near-irrecuperable loss, remains 
unexplained or ambiguous is indicative of the repressions that I argue are crucial to the structure of the film. If this is a death in Vietnam, the film's steadfast refusal to connect the father's overbearing patriarchal presence with a structure of feeling that allowed the drafting of their son to fight in the war, or situating the death in a historical and ideological context, is surely deliberate. The radical interiorization of this event, bracketing off social or political dimensions to make this strictly about the loss of a son or brother, makes the response to the loss seemed an index of a more fundamental incapacity, of a howling lament rather than a shout of anger, a turning inward that marks both family and film, despite what seems to be the 'macrocosmic' implications of its cosmological visual register.

This, then, is the first of many silences in the film. Here, I wish to turn to the work of Pierre Macherey, and in particular A Theory of Literary Production (1978/1989), to explicate a Marx-inflected mode of reading textual gaps, silences and repressions, before connecting this with critics of the classic melodrama of the 1950s, many of whom propose a kind of crisis or structural dissonance within the genre that is caused by its incapacity to deal with the social and ideological structures that produce it. A Theory of Literary Production proposes a dislocation between form and content: what the text says is its 'content', but what it does not say or is unable to say, its formal reticence or silences, is what reveals the unsayable of ideology, the things ideology works to conceal or mask. In the chapter 'The Spoken and the Unspoken', Macherey argues that 'the speech of the book comes from a certain silence [....] [T] he book is not self sufficient; it is necessarily accompanied by a certain absence, without which it could not exist'; 'Silence reveals speech - unless it is speech that reveals the silence' (Macherey 
1978/1989: 85; 86). The silences, the ideological gaps, indicate the points at which the formal or generic structures of the text become disjointed or incoherent, revealing the ideological imperatives of what may or may not be expressed. In a sense, Macherey psychologises the text: it is subject to a form of repression. For The Tree of Life, the moment of the announcement of the death of

R.L. is one of those silences, a revealing gap which indicates what may not be said in the United States of 2011: that it still sends its sons overseas to die in wars (from Vietnam to Iraq and Afghanistan), sacrifices to ideological imperatives of late-capitalist and neo-imperialist conflict. The trauma is ongoing.

If The Tree of Life can be read as an appropriation of, or homage to classic 1950s melodrama, then its enactment of that genre's own pervasive dissonances and crises of representation are perfectly attuned to the period of the War on Terror, and more particularly Obama's first Administration, whereupon a determination to undo the prosecution of war and massively enhanced security apparatuses of the Bush years quickly ebbed away: there was no closure of Guantanamo, and drone strikes intensified. R.L. becomes an emblematic sacrifice to an American guerre sans nom, one that does not end. As we shall now see, critics of the classic screen melodrama have theorised the genre in terms that are key to this essay: hysteria, excess, ideological dissonance and incoherence, Freudian repression and symptomatic return.

David N. Rodowick, in 'Madness, Authority and Ideology: The Domestic Melodrama of the 1950s' draws upon the ideological criticism of Pierre Macherey and Terry Eagleton to identify 'the social, psychic, and formal determinations [that] are equally predisposed towards developing internal incoherencies within the system of the melodramatic text' as they are to 
mutually reinforcing one another (Rodowick 1987: 269). Rodowick particularly focuses upon the figure of the male 'head of the family' as 'the figuration of patriarchal authority' and develops a reading of familial relations in which 'the family both legitimises and conceals sexuality by restricting it to a social economy defined by marriage' (Rodowick 1987: 271). This economy is read through the historical specificities of the post-war United States, in which 'the necessity of redefining and re-establishing the pace of the individual in the social formation became crucial' (276). Rodowick goes on to suggest that the melodrama stages the particular tension between individual, family and wider social and ideological formations:

The ideals that one's future could be self-determined and that prosperity was assured through individual labour and adherence to the system, were largely contradicted by the aggressive expansion of corporate capitalism along with a burgeoning system of bureaucracy. [...] It is precisely by virtue of the distance between the demands of the general ideology of post-war American society and the impossibility of their fulfilment according to the logic of melodramatic conventions that we can trace the specificity of the domestic melodrama by mapping out the network of resistances in which its narratives fail. (Rodowick 1987: 277-8)

Rodowick then places the Father-figure in melodrama as a kind of aporia or unresolvable paradox, in which the former guarantor of the system's stability becomes the very element through which it is destabilised:

Where the melodramatic father formally functioned to legitimate the system of conflict and guarantee its resolution by successfully identifying its heroes on the side of the law, morality, and authority, in the 1950s he functions solely to throw the system into turmoil by his absences to death or desertion, his weaknesses, his neglect, etc. (Rodowick 1987: 278)

Rodowick then makes a crucial turn to genre and form that is key to my own argument in this chapter. He proposes that 'the contemporary demands of ideology had become partially disjunct with the set of formal conventions which 
were required to articulate them' (278):

Incapable of formulating a convincing happy end which 'could reconcile the suffering individual to his social position', the domestic melodrama could only 'produce ideological discourses as to display a variable degree of internal conflict and disorder - a disorder produced by those displacements and mutations of ideology forced upon the text by the necessity to arrive, in accordance with the laws of its aesthetic production, at a "solution" to its problems' ([citing Terry Eagleton, Criticism and Ideology 86] Rodowick 1987: 278)

The incapacity of the genre or mode to find a structural solution to ideological problems, then, as posited as a key characteristic of the development of the melodrama of the 1950s: that it at once stages and reproduces the ideological dissonances which are its ground of cultural production. This irresolvable tension, I suggest, is also true of the neo-melodrama of The Tree of Life, which cannot find a 'solution' to the problem of the death of R.L. within the generic limits of what can be said or represented within the form of melodrama. Instead, it turns to the register of cosmological fiction, the mode of the Sublime.

This is entirely consistent with the conception of the 'postmodern sublime' articulated by Jean-François Lyotard which, as we saw above, is influential upon the work of Cathy Caruth on cultural narratives of trauma and the limits of representation. Roger Luckhurst writes: 'For post-trauma aesthetics, Lyotard turned to the theory of the sublime, where representing the very failure to process the overwhelming event paradoxically figures its success as a work of art' (Luckhurst 2008: 5-6). This idea is taken up in terms of melodrama by Sarah French and Zoë Shacklock, who argue that:

[the] postmodern sublime, 'the unrepresentable in presentation itself', unable to be represented but present nonetheless, thus better reflects the virtuality if affect. The postmodern sublime dispenses with the rules of representation, not in order to re-establish new ones, but simply to 
'better produce the feeling that there is something unrepresentable'. Therefore, while the encounter with the sublime may not be cognitively grasped, it remains present and felt in the realm of affect. (French and Shacklock 2014: 345)

In this article, French and Shacklock connect the postmodern sublime with The Tree of Life's 'birth of the universe sequence', what I have called the cosmological register of science fiction effects spectacle. They suggest that despite the deployment of 'sublime images of the birth of the universe', The Tree of Life turns to the 'postmodern sublime' as the images 'signify[...] things that lie beyond [the cinematic] frame' (French and Shacklock 2014: 346). In their reading, the effects sequences themselves mark the limits of the representable (i.e. divine Creation). The film points outside of itself theologically.

In a film in which temporal disjunction is a key formal principle, after the trauma of R.L.'s death in the 1960s, the film returns to the beginning cosmologically. In an extraordinary 10-minute sequence, we are shown the beginnings of the universe (using images from the Hubble telescope), of Earth, of life growing in the oceans, and then on land: the dinosaurs, in perhaps the most well-known disjunctive imagery presented in The Tree of Life. While Moritz Pfeifer, in 'Either and Or: On Terrence Malick's The Tree of Life' (2011) makes an interesting case for the centrality of the later Jack's point-of-view with regard to the presentation of 1950s small-town life and in particular the idealisation of the mother-figure, this sequence seems like a sleight-of-hand. Does Jack, sitting in his architect's office, daydream of the beginning of Creation? Or is the film's narration at this point elided with Jack's? We are, of course, presented with many scenes in the film at which Jack is not present, and the arrival of the telegram is one of those. In the cosmological spectacle sequence, it would seem that Jack's 
point-of-view is stitched into the film's own, and this is entirely at the service of a sense of awe and wonder: the rhetoric of the sublimity of science fiction cinema in the service of a theological vision.

In a very curious scene in this sequence, an enfeebled dinosaur lies on a river beach, while a raptor proceeds towards fallen prey, but when it reaches this easy meal, the predator steps on it a couple of times, then moves off. Although The Tree Of Life shows the development of life on Earth as a natural process, in events recognisable from conventional natural history, this is also signally a work of Creation. (The same mixture of natural selection and Biblical/ transcendent motifs can be found in 2001: A Space Odyssey, one should note.) The title of the film is itself ambiguous, and could refer to either life as nature, the branching 'tree' of natural selection; or it could refer to the 'tree' of the 'Great Chain Of Being', a spiritually-invested understanding of nature which places human beings at the top (or end) of the 'tree' of nature. In The Tree Of Life, what seems to be a world of natural processes actually privileges the theological, the immanence of the divine, for the dinosaur seems to show, if not compassion, then mercy: it decides not to eat the easy meal. The raptor lies down with the lamb. What this signifies is that the way of Nature is throughout underpinned by Grace: the seeming dichotomy is no binary at all. While this foreshadows the visionary sequence on the beach at the end of the film, where Jack is reconciled with R.L. his father and mother, it is profound and troubling effects for the depiction of trauma and the potential for a textual therapeutics. There is no coming to terms with the loss of the son/brother except in death, or rather, in a vision of a redemptive life after life. It is only when life does not go on, that grace, that redemption or salvation, enters. This, of course, runs entirely counter to the 
huge cosmological narrative invoked in the first part of the film, which insists, visually, that life does go on, that death and life (and death) turn and turn about, are a part of the same natural cycle and process.

The rupture of the trauma of the death of R.L. is, then, an event that the generic structures of melodrama cannot resolve. There is no 'happy ending' possible, as Rodowick notes, which will reconcile the suffering individual (Jack, the Father, the Mother) to the social and ideological formations which motivate the death of the beloved son. Instead, then, The Tree of Life must turn outside the genre of melodrama to find the means by which to resolve the narrative. This is different from the kind of symptomology suggested by critics of melodrama towards its aesthetics of 'excess', its visual and narrative 'hysteria', which are mentioned by so many. Christine Gledhill, in an introduction to the collection Home Is Where the Heart Is (1987), suggests that it is the kind of ideological criticism essayed by Rodowick and others that "looked to stylistic "excess" and narrative disjuncture for their "exposure" of contradictions between a mainstream film's aesthetic and ideological programmes' (Gledhill 1987: 6), but we can find the language of 'excess' in other approaches, particularly those who use the language and analysis of psychoanalysis. ${ }^{1}$ Geoffrey Nowell-Smith, for instance, writes:

The laying out of the problems 'realistically' always allows for the generating of an excess which cannot be accommodated. The more the plots press towards a resolution the harder it is to accommodate the excess. What is characteristic of the melodrama, both in its original sense and in the modern one, is the way the excess is siphoned off. The undischarged emotion which cannot be accommodated within the action, subordinated as it is to the demands of family/ lineage/ inheritance, is traditionally expressed in the music and, in the case of film, in certain elements of the mise-en-scène. [...] The mechanism here is strikingly similar to that of the psychopathology of hysteria. In hysteria [...] the 
energy attached to an idea that has been repressed returns converted into a bodily symptom. (Nowell-Smith 1987: 73)

Nowell-Smith goes on to propose that '[o]ften the 'hysterical' moment of the text can be identified as the point at which the realist representative convention breaks down' (74). Although the way in which the melodramatic 1950s narrative is itself presented in The Tree of Life is far from the conventions of cinematic realism, the shift into the cosmological Creation sequence indicates another removal again, into a different generic register. This, then, following directly on from the traumatic delivery of the news of R.L.'s death, is the textual symptom, the moment of 'hysteria', in which the ideological aporia of the text, its 'silence' or moment of unrepresentability, can be found. It is not in the unrepresentability of the divine (the techniques of the postmodern sublime); rather, it is in the unrepresentability of the social and ideological effects of trauma.

David Rodowick, Thomas Elsaesser (in the well-known essay 'Tales of Sound and Fury: Observations on the Family Melodrama' (1987)) and others argue that the contradictions of melodrama, particularly to do with the tensions between desire and the regulatory law of family and social order, cannot be resolved within the generic system because its relentless interiority offers no recourse to wider socio-cultural or ideological formations - what Pam Cook calls a 'closed, hysterical world' (Cook 1991: 249). This results in a symptomology of 'excess' (visual stylization, 'emotional' musical score) which acts as a return of the repressed matter in another form. In The Tree of Life, the central traumatic loss cannot be resolved within a textual therapeutics; there can be no 'happy ending' within the melodramatic narrative, and the Oedipal conflict between Father and son Jack (where Jack shouts at his father 'She only loves me!'), drawn 
from classic 1950s melodrama, is resolved extraordinarily easily, almost a kind of empty gesture of reconciliation which throws the wider failure of resolution into relief. Instead of a deus ex machina, a 'God out of the machine' that arrives to close the narrative, what we have in The Tree of Life is a deus extra machina, a God outside of the generic machine, where science fiction resolves melodrama, and theology becomes the necessary supplement to resolve the contradictions of ideology. This is what we might call the 'cosmological fix', and is directly analogous to the underpinning of Nature by Grace that I alluded to earlier in the essay. Grace is the thing outside, the immanence of the divine, that which is in excess of the Nature but which it striates and redeems.

To conclude, I wish to suggest a further reading of The Tree of Life in relation to its context of production and release, some decade after $9 / 11$, in the administrative phase of the War on Terror. Other Hollywood films have dealt with the problem of trauma and US military involvement overseas through the emblematic figure of the soldier, most notably in Kathryn Bigelow's Oscarwinning The Hurt Locker (2008), where the motif of the failure of social reintegration, common to the experience of Vietnam veterans and films such as Hal Ashby's Coming Home (1978), itself returns in a different but parallel historical context. $^{2}$ As I suggested above, The Tree of Life is a film made in the time of war, even if not a 'war film', and its silences and aporias, and in particular its 'theological turn', can be read as a kind of symptom in itself, of a culture and society that still struggles to bring itself to speak the ideological reasons for ongoing individual and social trauma following 9/11, and military involvement in Iraq and Afghanistan. One must ask, therefore, whether The Tree of Life deliberately stages these strategies and silences in order for us to see them. I 
suspect not. While I would wish to downplay neither the very evident and sincere faith encoded into The Tree of Life, nor the acute critical readings of the film in its own theological terms, what the film reveals is a fundamental incapacity: for contemporary US culture to truly come to terms with the legacy of its own recent traumas.

\section{Bibliography}

Baker, Brian (2015), Contemporary Masculinities in Fiction, Film and Television (London: Bloomsbury)

Bukatman, Scott (2003) Matters of Gravity: Special Effects and Supermen in the 20th Century (Durham NC and London: Duke University Press)

Caruth, Cathy, Unclaimed Experience: Trauma, Narrative and History (Baltimore MD: The Johns Hopkins Press, 1996)

Cook, Pam (1991), 'Melodrama and the Women's Picture', Imitations of Life: a reader on film and television melodrama, ed. Marcia Landy (Detroit MI: Wayne State University Press), 248-267

Elsaesser, Thomas (1987) 'Tales of Sound and Fury: Observations on the Family Melodrama', Home Is Where the Heart Is: Studies in Melodrama and the Woman's Film, ed. Christine Gledhill (London: BFI), 43-69

French, Sarah and Zoë Shacklock (2014), 'The affective sublime in Lars von Tier's Melancholia and Terrence Malick's The Tree of Life', New Review of Film and Television Studies, 12:4, 339-356

Freud, Sigmund (1955b) 'Appendix: Memorandum on the Electrical Treatment of War Veterans' (1920), Standard Edition of the Complete Psychological 
Works of Sigmund Freud, vol. XVII, trans. and ed. James Strachey (London: Hogarth Press), pp.211-215

Freud, Sigmund (2006) 'Beyond the Pleasure Principle', The Penguin Freud reader, Adam Phillips, ed. (London: Penguin), pp.132-195

Freud, Sigmund (2010) The Wolf-Man, trans. Louise Adey Huish (London: Penguin)

Freud, Sigmund and Joseph Breuer (1956) Studies on Hysteria, trans. James and Alix Strachey (London: Hogarth Press)

Gates, Philippa (2001) 'The Man's Film: Woo and the Pleasures of Male Melodrama', The Journal of Popular Culture, 35: 1, 59-79

Handley, George B. (2014) ‘Faith, Sacrifice, and the Earth’s Glory in Terrence Malick's The Tree of Life', Angelaki: Journal of the Theoretical Humanities 19:4, 79-93.

Kaplan, E. Ann (2005) Trauma Culture: The Politics of Terror and Loss in Media and Literature (New Brunswick NJ and London: Rutgers University Press) Kilbourn, Russell J.A. (2014), '(No) Voice Out of the Whirlwind: The Book of Job and the End of the World in A Serious Man, Take shelter, and The Tree of Life', Adaptation 7:1, 25-46

Kilby, Karen, Luke Timothy Johnson and Bernard G. Prusak (2014), 'Seeing as God Sees: Terrence Malick's The Tree of Life', Commonweal 10 January $2014,10-18$

Kirby, Lynne (1997) Parallel Tracks: The Railroad and Silent Cinema (Exeter: University of Exeter Press)

Kirby, Lynne (1997) Parallel Tracks: The Railroad and Silent Cinema (Exeter: University of Exeter Press) 
Kleinhans, Chuck (1991) 'Notes on Melodrama and Family under Capitalism', Imitations of Life: a reader on film and television melodrama, ed. Marcia Landy (Detroit MI: Wayne State University Press), 197-204

Lifton, Robert Jay (1973) Home from the War: Vietnam Veterans, neither victims nor executioners (New York: Simon and Schuster)

Luckhurst, Roger (2008) The Trauma Question (London: Routledge)

Lyotard, Jean-François (1992) "Answering the Question: What is Postmodernism?', Postmodernism: A Reader, ed. Patricia Waugh (London: Edward Arnold), 117-124

Macherey, Pierre (1989) A Theory of Literary Production (1978) trans. Geoffrey Wall (London: Routledge)

Nowell-Smith, Geoffrey (1987), 'Minelli and Melodrama', Home Is Where the Heart Is: Studies in Melodrama and the Woman's Film, ed. Christine Gledhill (London: BFI), 70-74

Pfeifer, Moritz (2011), 'Either and Or: Terrence Malick's The Tree of Life, Senses of Cinema 60. http://sensesofcinema.com/2011/feature-articles/eitherand-or-on-terrence-malicks-tree-of-life/. Accessed 30/8/2015

Plate, S. Brent (2012) 'Visualising the Cosmos: Terrence Malicks' The Tree of Life and Other Visions of Life in the Universe', Journal of the American Academy of Religion, 80:2, 527-536

Rodowick, David N. (1987) 'Madness, Authority and Ideology: The Domestic Melodrama of the 1950s', Home Is Where the Heart Is: Studies in Melodrama and the Woman's Film, ed. Christine Gledhill (London: BFI), 268-280 
Schatz, Thomas (1991) 'The Family Melodrama', Imitations of Life: a reader on film and television melodrama, ed. Marcia Landy (Detroit MI: Wayne State University Press), 148-167

Sinnerbrink, Robert (2012) 'Cinematic Belief', Angelaki: Journal of the Theoretical Humanities 17:4, 95-117

Sterritt, David (2011) 'Days of Heaven and Waco: Terrence Malick's The Tree of Life, Film Quarterly 65:1, 52-7

\section{Filmography}

Malick, Terrence (dir.), (2011) The Tree of Life (River Road Entertainment/ Fox Searchlight)

Malick, Terrence (dir.) (1998) The Thin Red Line (Fox 2000/ Phoenix Pictures)

Kubrick, Stanley (dir.), 2001: A Space Odyssey (Warner Brothers)

Ashby, Hal (1978) Coming Home (United Artists)

Bigelow, Kathryn (2008) The Hurt Locker (Voltage Pictures/ Summit Entertainment)

\footnotetext{
1 See Kleinhans (1991), Cook (1991), Schatz (1991), Gates (2001).

2 I have written on The Hurt Locker in Contemporary Masculinities in Fiction, Film and Television (2015).
} 